\title{
As condições de possibilidade das ocupações de terra*
}

Lygia Sigaud

O cupar terras e nelas montar acampamentos tornou-se, nos últimos vinte anos, a forma apropriada para reivindicar a reforma agrária no Brasil. D ela se valem o M ovimento dos Trabalhadores Rurais Sem Terra (M ST), o movimento sindical e outras tantas organizações existentes no mundo rural. 0 Estado brasileiro tem conferido legitimidade à pretensão dos movimentos (como se autodenominam e são denominadas essas organizações), ao desapropriar as fazendas ocupadas e redistribuir as terras entre os que se encontram nos acampamentos.

Esse tipo de ocupação constitui fato novo na história brasileira. Asocorridas no período anterior a 1964, como as do Rio G randedo Sul edo estado do Rio deJ aneiro ${ }^{1}$, não tinham as mesmas características e amplitude das que se generalizaram nos últimos vinte anos, nem se tornaram a forma adequada de demandar desapropriação de terras. $\mathrm{H}$ avia outras maneiras de fazêlo, notadamente as mobilizações pela mudança na Constituição². Com o golpe militar de 1964, tornou-se impossível promover ocupações. As terras assim obtidas foram devolvidas aos seus proprietários e os militantes das organizações de trabal hadores rurais tornaram-se alvo da repressão policial e militar.

A partir do final dos anos de 1970 as ocupações foram retomadas no Rio Grande do Sul, sempre associadas à instalação de acampamentos com dezenas, centenas de famílias. As primeiras ocupações, organizadas por
*U maversão preliminar deste texto foi apresentadano XXVIII Encontro Anual daAnpocs, em Caxambu (MG), out. 2004.

1. Sobre as ocupações de terra ocorridas no período, ver, para o Rio Grande do Sul, Eckert (1984) e Rosa ePalmeira (2004); para o estado do Rio de Janeiro, Grynzpan (1987) e Ernandezet alii (2004).

2. Sobreas pressões pela reforma agrária, ver Camargo (1981). 
3. As palavras grifadas correspondem a categorias nativas. Colono éo termo que designa os descendentes dos imigrantes alemães, italianos e poloneses que se estabeleceram no Sul do país a partir de 1824, como pequenos produtores.

4. A região canavieira de Pernambuco éuma das zonas demais antiga coIonização do país. No século XVI osportugue ses ali implantaram a agricultura da cana e o fabrico do açúcar. D esde o final do século XIX a cana é explorada em grandes propriedades por fornecedores e usineiros, e emprega uma mão-de-obranumerosa. Paraumahistóriadasre lações sociaisno mundo dos engenhos, ver $C$ orrea de Andrade (1964; 1989), Eisenberg (1977), Mello (1975), Palmeira (1971; 1976); Sigaud (1979), Garciaj r. (1983) e H eredia (1979).

5. R ealizada por pesquisadores do M useu Nacional da U niversidade Federal do Rio deJaneiro e da École N ormale Supérieure (ENS), de Paris, com financiamento da Fundação Ford, da Fundação U niversitária dePesquisasJoséBoni- colonos $^{3}$, tinham forte apoio da Comissão Pastoral da Terra (CPT ), vinculada à I greja C atólica. Esse núcleo criou, em 1984, o M ovimento dos Trabalhadores Rurais Sem Terra, o M ST (cf. Stedile e M ançano, 1999; M ançano, 2000). Em meados da década de 1980, graças a uma política de expansão da organização, há regi stros de ocupações em vários estados brasileiros. Em 1993, o Congresso N acional estabeleceu que a improdutividade das terras caracterizava o não-cumprimento da função social da propriedade, caso previsto pela Constituição de 1988 para proceder à desapropriação. As ocupações generalizaram-se em todo o país, promovidas não apenas pelo M ST, mas também pelos sindicatos de trabalhadores rurais e por dezenas de outras organizações criadas com o objetivo precípuo de ocupar terras. N esse período, o Instituto N acional da Reforma Agrária (Incra), que até então tinha uma atuação modesta, começou a desapropriar as terras ocu padas e a redistribuí-las entre os acampados, tornando-os parceleiros, isto é, titulares de uma parcela de terra. As ocupações, os acampamentos e as desapropriações a eles associadas indicam, portanto, uma inflexão no modo de proceder das diversas organizações no mundo rural e do Estado. D aí poder-se falar de um fato novo.

Para analisar essa mudança tomarei como ponto de partida o caso de Pernambuco, estado da federação com o maior número de ocupações de terras desde a segunda metade da década de 1990. A Zona da M ata éa região onde se registra uma concentração expressiva de acampamentos, instal ados em engenhos, como são denominadas as grandes plantações produtoras de canade-açúcar ${ }^{4}$. Procurarei inscrever as ocupações na história recente da região canavieira, mostrar as condições sociais que contribuíram para que ocupar e acampar se tornasse a forma apropriada de reivindicar a reforma agrária, e examinar as implicações dessa tranfformação social. Para isso, buscarei amparo em pesquisa empírica desenvolvida desde 1997 nos municípios de Rio Formoso eTamandaré, situados no litoral sul do estado, sobre as ocupações de dezesseis engenhos (C amaçari, Amaragi, Serra d'Água, M inguito, M ato Grosso, São M anuel, Cipó, São João, Brejo, M amucaba, Jundiá de C ima, Coqueiro, Saué Grande, Sauezinho, M ascatinho e Laranjeiras), ocorridas entre 1992 e $2000^{5}$.

Como conclusão, farei uma digressão sobre o caso da África do Sul ${ }^{6}$, onde as ocupações são entendidas pelo Landless People's M ovement, que reivindica uma forte inspiração nas ações do M ST, como o procedimento a ser adotado para pressionar o governo no sentido de restituir as terras confiscadas às populações pelos ingleses em 1913, redistribuir terras con- 
centradas nas mãos dos brancos e garantir direitos sociais e posse da terra para os que nelas trabalham, medidas previstas na legislação pós-apartheid. As ocupações de terra registradas em algumas províncias não possuem as mesmas características das que ocorrem no Brasil: visam a assegurar terras para moradia, e não para produção, como em Bredell, nas imediações de J ohannesburg, ocorrida em 2001. N ão se observa, como aqui, uma espiral de ocupações, mas uma espiral de ataques às fazendas e assassinatos de trabal hadores negros efazendeiros brancos (cf. ICG , 2004; Steinberg, 2002). Ao comparar os dois países, buscarei identificar as condições sociais que no caso brasileiro têm favorecido a institucionalização das ocupações de terra e no caso sul-africano as têm obstaculizado.

\section{A forma acampamento}

A primeira ocupação de que se tem notícia em Rio Formoso foi organizada por militantes do M ST, como são chamados seus quadros, e sindicalistas do município7. Em abril de 1992, cerca de 1.200 pessoas (homens, mulheres e crianças) entraram no engenho $C$ amaçari, instalaram um acampamento e reivindicaram a desapropriação das terras. $\mathrm{A}$ imprensa noticiou o fato como uma mobilização por emprego e cestas básicas: os jornalistas ainda não dispunham de categorias de percepção que Ihes permitissem reconhecer estar diante de um fato novo ${ }^{8}$.

Camaçari era tido como patrimônio da Rede Ferroviária Federal. O s donos da U sina Cucaú conseguiram provar que o engenho Ihes pertencia e 0 juiz da comarca determinou o despejo dos ocupantes por uma força policial formada por centenas de homens. M uitos voltaram para suas casas. Cerca de oitocentos deles, no entanto, remontaram o acampamento em Vermelho, área de pequena propriedadeem Rio Formoso, ea partir de lá iniciaram uma saga de ocupações em engenhos que, conforme critérios do Incra, poderiam ser considerados improdutivos e, portanto, passíveis de desapropriação. Elas foram promovidas conjuntamente por militantes do M ST e pelos sindicalistas de Rio Formoso até1996, quando estes passaram a organizálas sozinhos.

A partir da reconstituição dos diversos acampamentos, foi possível perceber seus aspectos recorrentes. Após a entrada no engenho, à noite ou ao amanhecer, os participantes buscavam locais altos e visíveis, próximos às matas e aos cursos d'água. Lá armavam as barracas com a madeira que retiravam da mata, as cobriam com folhas e, por fim, com um plástico preto grosso, que denominavam lona. As barracas eram alinhadas de modo fácio (FUJB), da Fundação do Amparo à Pesquisa do Estado do Rio dejaneiro (Faperj), do Conselho Nacional de $D$ esenvolvimento Científico eTecnológico (CN Pq) edaEN S. Para estetexto foram retoma das análises anteriores (Sigaud, 2000; Sigaud et alii, 2001), o material reunido para a exposição Lonase bandérasem teraspernambucanas (www.lonaseban deiras.com.br) eestudos feitos namata pernambucana. 0 corpusanalisado éconstituído deentrevistas e histórias de vida dos que participaram das ocupações, da observação feita nos acampamentosededocumentação do Incra.

6. A digressão sul-africanaapóiz-seno exameda literaturaacadêmicaeda documentação disponível, eem entrevistascom líderes e trabal hadores do meio rural realizadas durante duas visitas à província de KwaZulu$N$ atal (2003 e 2004).

7.0sSindicatos deTra balhadores Rurais estão organizados a partir de uma base municipal. $\mathrm{N}$ a mata pernambuca na, a grande maioria dos associados é cons- 
tituída por assal ariados dos engenhos.

8. "A invasão da área se deve às conseqüências do período de entressafra, quando acaba 0 corte da cana e os trabalhadores rurais não têm como sobreviver." Ver Jornal do Commércio (1992).

9. Paraareconstituição de uma ocupação na mata pernambucanaem 1999, ver Smircic (2000, pp. 29-55).

10. Entreos comportamentos alvos de forte censurafiguram os abusos al coólicos e 0 emprego da força física ou de armas na regulação de conflitos. $N$ em sempre, no entanto, culminam em expulsão, que depende da avaliação da coordenação e do conjunto dos acampados. a formar ruas. A montagem do acampamento compreendia também a instalação de um mastro elevado no qual era içada a bandeira da organização que o estava promovendo9. No começo era utilizada apenas a bandeira do M ST, já que os sindicatos só viriam a ter suas próprias bandeiras quando a Federação dosTrabal hadores na Agricultura do Estado de Pernambuco, a Fetape, que nucleia os sindicatos, passou a incluir em sua programação as ocupações de terra.

0 número de participantes era variável, podendo ir de mais de cem, como no caso do engenho São João, ocupado em 1996, até pequenos grupos, como os nove que ocuparam o Brejo em 1997. Após a ocupação e a montagem das barracas, o número de envolvidos tanto podia crescer, com a chegada de mais pessoas, e o exemplo é novamente o Brejo, que chegou a contar com mais de sessenta acampados, quanto diminuir, como ocorreu em São João, onde restaram apenas dezenove pessoas, eC ipó (ocupado em 1993), que passou de oitenta a 35 ocupantes. As reduções davam-se pela saída espontânea ou pela exclusão daqueles cujo comportamento era considerado inaceitável pelos demais ${ }^{10}$.

D 0 ato da ocupação tendiam a participar preferencialmente os homens adultos; mulheres e crianças chegavam depois. A montagem da barraca sinalizava a partici pação no acampamento. 0 s indivíduos não permaneciam ali todo o tempo, pois a mai oria não interrompia as atividades destinadas à manutenção da família, saindo para trabal har nos canaviais, fazer biscates na construção civil, atuar como vigias ou vendedores ambulantes, catar caranguejos nos mangues etc., enquanto as famílias ficavam cuidando das barracas. $\mathrm{H}$ avia ainda aqueles que passavam longos períodos fora, deixando a barraca fechada, sozinha, ou um parente ou conhecido tomando conta. Periodicamente retornavam e assi $m$ reafirmavam seus laços com os demais.

Em todos os acampamentos havia uma divisão do trabal ho organizada em comissões, como as encarregadas da segurança, que zelava pelo acampamento, sobretudo à noite, e da alimentação, que administrava o aprovisionamento dos participantes. Os movimentos tratavam de conseguir dos órgãos governamentais, sobretudo o Incra, mas também das prefeituras, dos vereadores e das igrejas locais, alimentos para os acampados, além de promover pedágios nas estradas para arrecadar dinheiro e col eta de gêneros nos estabelecimentos comerciais.

O s participantes dos acampamentos eram oriundos da própria região canavieira, ainda que alguns procedessem do agreste, zona vizinha com pequenas propriedades. $\mathrm{O} s$ adultos tinham uma história de trabalho e de 
vida nos canaviais. Alguns haviam exercido outros ofícios, como pedreiros, serventes, condutores de caminhões e tratores, vigias, vendedores ambulantes e domésticas. $\mathrm{H}$ avia famílias com filhos pequenos e adolescentes, mas também indivíduos sós, pessoas que ainda trabalhavam e aposentados. M uitos se dirigiam aos acampamentos após convite dos militantes do M ST ou de sindicalistas. 0 trabalho de mobilização era realizado nas pontas de rua, nome dado às periferias das pequenas cidades da Z Zna da $\mathrm{M}$ ata, onde residem aqueles que se situam nas posições mais baixas da hierarquia social: os trabalhadores manuais. Eram convidados também, nos engenhos, aqueles trabalhadores que possuíam um contrato de trabalho.

A duração dosacampamentos era variável, podendo ser de meses, quando eram desfeitos com a desapropriação das terras, ou anos, como no caso de M amucaba, acampamento iniciado em 1998 e que ainda estava montado em 2004. Q uase todos os acampamentos da área foram desfeitos após mandato judicial, quando os proprietários das terras requereram a reintegração de posse, concedida pelo juiz da comarca. Aos despejos seguia-se via de regra a remontagem do acampamento no mesmo local ou em suas imediações, na beira das estradas ${ }^{11}$. M uitos estiveram sujeitos também aos ataques de milícias privadas de fazendeiros, que agiam por conta própria para desalojar os ocupantes, como ocorreu em M ascatinho, Jundiá de Cima e M ato Grosso.

A pós a primeira ocupação, o engenho tornava-se objeto de reivindicação da desapropriação, e os participantes transformavam-se em pretendentes à redistribuição das terras. M esmo quando não estava localizado nas terras pretendidas, 0 acampamento permanecia a elas associado e era reconhecido pelo nome do engenho. Assim, o acampamento de Cipó, despejado logo após a ocupação, esteve estabelecido durante mais de um ano na localidade vizinha de Vermelho; o de M ato Grosso, esvaziado após ataque das milícias, estabeleceu-se numa parcela de M inguito, já desapropriado; e o de Jundiá, atacado no dia da ocupação por mais decem homens reunidos pelo fazendeiro, fixou-se na beira da estrada.

H avia um vocabulário próprio associado às ocupações e aos acampamentos. Dizia-se preferencialmente ocupar em vez de invadir, verbo este empregado pela mídia, pelos proprietários e pelo senso comum. Para descrever a ocupação individual, os trabalhadores utilizavam o verbo entrar. Q uando chegavam com a intenção de entrar, perguntavam antes ao coordenador responsável se havia vaga, como se estivessem procurando um emprego. 0 objetivo da entrada era pegar terra, e a vida no acampamento era freqüentemente descrita como um estar debaixo da lona preta, o que
11.0 mandato judicial dereintegração valeape nas para promover um despejo. Q uando a terra é reocupada, o proprietário deve solicitar novareintegração, o que muitos preferem não fazer. 
12. Foram eles: Amara gi, Serra d'Água, M inguito e M ato Grosso, em Rio Formoso, e Cipó, São João, Saué Grande, Sauezinho, Cocal, Cocalzinho, Coqueiro, Jundiá deCima, Laranjeiras, M ascatinho, Brejo el lhetas. sinalizava uma situação de penúria e de sujeição às intempéries (chuva, calor excessivo durante o dia e frio à noite).

O s acampamentos eram, portanto, muito mais do que a mera reunião de pessoas para reivindicar a desapropriação de um engenho. Compreendiam técnicas ritualizadas de realizar a ocupação, uma organização espacial, uma etiqueta para entrar no acampamento e nele se instalar, regras para ali conviver, um vocabulário próprio e elementos dotados de forte simbolismo, como a bandeira ea lona preta, que constituíam os marcos distintivos. Essa combinação de aspectos modelares constitui uma forma, a forma acampamento (cf. Sigaud, 2000). Trata-se de um modelo engendrado no Sul do país, ao longo do processo que desembocou na constituição do M ST. Seus militantes, deslocados para o N ordeste, ali o implantaram e, na mata pernambucana, o modelo foi progressivamente ajustado às condições locais.

Entre 1987 e 2003, o Incra desapropriou 194 propriedades em Pernambuco, entre as quais dezesseis engenhos ${ }^{12}$, na área compreendida pelos municípios de Rio Formoso e Tamandaré (o antigo distrito emancipado em 1996), e contemplou com parcelas de terra os que já residiam e trabaIhavam nos engenhos, conforme determina a legislação, e também os que se encontravam acampados. Em catorze delas tinham ocorrido ocupação e estabelecimento de acampamentos, o que revela a estreita relação entre a forma acampamento e as desapropriações promovidas pelo Estado.

A crença na lona preta

A implantação da forma acampamento na mata pernambucana nada tem de evidente. $\mathrm{N}$ ão há elementos na história recente da região que autorizem a supor que o território dos engenhos, tradicionalmente sob o controle estrito dos patrões, viesse a ser ocupado com acampamentos; que 0 M ST viesse a agir junto à massa de trabalhadores ali onde os sindicatos tinham uma hegemonia incontestável; que os sindicalistas passassem a ocupar terras; e que os trabalhadores se dispusessem a ocupar propriedades de outrem. Para entender como tais desdobramentos se tornaram possíveis é preciso examinar as ocupações e os acampamentos a partir de quadros sociais e históricos mais amplos.

N o final da década de 1980, o governo brasileiro alterou suas diretrizes em relação à agroindústria açucareira, na esteira de uma política mais geral de retirada do Estado da economia: suprimiu os subsídios que há décadas garantiam o preço da cana e do açúcar; privatizou as exportações que até 
então eram feitas pelo Instituto do Açúcar e do Álcool; e permitiu a elevação da taxa de juros. Essas medidas, assim como uma grande seca ocorrida no período, desencadearam uma crise no setor. M uitos patrões, fossem eles industriais do açúcar ou fornecedores de cana, não lograram adaptarse à falta de proteção do Estado e faliram. 0 utros tantos trataram de se reestruturar. M ilhares de trabalhadores perderam o emprego, quer pela falência dos patrões, quer pelo downsize promovido pelas empresas em reestruturação (cf. Correa de Andrade, 2001).

No final dos anos de 1990, das quatro usinas que exploravam a cana na área estudada, apenas Trapiche, cuja sede está localizada em Sirinhaém (município limítrofe ao norte de Rio Formoso), estava em situação tida como sólida e equilibrada. Cucaú, sediada em Rio Formoso, saía de um pedido de concordata. Santo André, localizada em Tamandaré, não havia moído cana na safra de 1996-1997 e desde 1995 não honrava regularmente o pagamento dos trabal hadores. Central Barreiros, situada em Barreiros, ao sul deTamandaré, entregara ao Banco do Brasil treze de seus engenhos (nove dos quais local izados em Pernambuco equatro no estado vizinho de Alagoas) para pagar dívidas ehabilitar-sea novosempréstimos. Essa usina, quena safra de 1988-1989 havia moído quase 650 mil toneladas de cana, chegava à de 1996-1997 com uma produção de 350 mil toneladas ${ }^{13}$. N os engenhos explorados por fornecedores, denominados particulares, a queda de produção também era acentuada. Amaragi, um dos maiores engenhos de Rio Formoso, com uma produção de 30 mil toneladas de cana nos anos de 1970, produzia apenas 6 mil em meados dos anos de 1990. N esse engenho, como em outros, houve igualmente suspensões do pagamento dos saláriose, nessa época, 3 mil trabalhadores encontravam-se desempregados, segundo estimativa dos dirigentes sindicais. As ocupações ocorreram precisamente nesses engenhos falidos, onde as terras se tornaram improdutivas pelos critérios técnicos do Incra. Vulneráveis, muitos patrões não tiveram mais como garantir o território de seus engenhos e os trabal hadores desempregados tornaram-se o alvo privil legiado dos convites para realizar as ocupações.

Foi nessa conjuntura, e no âmbito de um processo de expansão pelo território nacional (cf. M ançano, 2000; Stedile e M ançano, 1999), que o M ST chegou à Zona da M ata pernambucana. No litoral sul, os militantes do M ST se aliaram aos sindicalistas e começaram a ocupar os engenhos, trazendo a tecnologia apropriada para ocupar terras, montar e administrar os acampamentos. O s sindical istas colaboraram com seus quadros, com os contatos entre os trabal hadores e com a infra-estrutura de que dispunham,
13. Ver Boletins de Safra (1989-1999), do Sindicato das Indústrias do Açúcar de Pernambuco, Recife, 1999. 
14. Ver www.mst.org. $\mathrm{br} / \mathrm{mstpe}, 2000$.

15. Em 1962, o governo federal regulamentou a lei que autorizava a criação desindicatosno campo. Ver Camargo (1983), Bezerra (1979) e Wilkie (1964).

16. Ver Diário de Pernambuco, 11 jun. 1997. sobretudo as instalações sindicais (cf. Rosa, 2004, p. 77). A ocupação de Camaçari, em 1992, foi produto dessa cooperação e é vista até hoje como um marco inaugural: "Tudo começou em Camaçari", costumam dizer com freqüência as lideranças e os trabalhadores que participaram desta e das ocupações subseqüentes, e é o que afirma explicitamente o M ST em sua história oficial ${ }^{14}$. A partir de então o MST logrou recrutar jovens e em pouco tempo montou uma rede de militantes que passou a atuar na área a serviço do movimento e de suas ocupações.

A aliança de sindicalistas de Rio Formoso com o M ST chama a atenção. Embora a reforma agrária fosse uma reivindicação sempre presente na agenda do movimento sindical, não se cogitava ocupar terras para obtêlas. Como mostra Rosa (2004), as pretensões de sindicalistas mais jovens de ascenderem no campo sindical e dos mais velhos de construir uma carreira na política municipal teriam contribuído para que tal aliança se produzisse no litoral sul naquele momento de crise da agroindústria açucareira. A partir de 1996 os sindicalistas passaram a montar sozinhos os acampamentos nos engenhos da região.

No plano estadual, a Fetape foi sendo progressivamente pressionada por alguns sindicalistas já participantes em acampamentos a incluir as ocupações em sua programação. N aquele momento, os sindicalistas não detinham mais o monopólio da representação dos trabalhadores, adquirido progressivamente a partir do início da sindicalização rural, em 1962 ${ }^{15}$, e estavam ameaçados de perder a força e o prestígio que desfrutavam em Pernambuco. Em 1997, a Fetape já ocupava tantas terras quanto o M ST ${ }^{16}$. A inflexão do movimento sindical deu um impulso espetacular às ocupações em Pernambuco, que aumentaram em progressão geométrica. Entre 1990 e 1994, o estado era o sexto em número de ocupações, com 28 de um total nacional de 421, e o quarto em famílias envolvidas, com quase 5 mil de um total de aproximadamente 75 mil. Entre 1995 e 1999, período no qual a Fetape também realizava ocupações, tornou-se o primeiro estado tanto em número de ocupações, 308 de um total de 1.855, quanto em número de famílias, 35 mil de um total de cerca de 256 mil (cf. M ançano, 2000, pp. 270-272).

Para os trabalhadores rurais da mata pernambucana, instalar-se por meio de ocupação em um engenho, sem a autorização do dono, para obter para si uma parcel a das terras desapropriadas dos patrões não fazia partedo horizonte de possibilidades. Eles só acediam a um engenho após terem sido aceitos para prestar serviços e se estabeleciam em locais designados pelo patrão e 
seus prepostos. H avia a utopia do engenho liberto (cf. Sigaud, 1979, pp. 205-222), no qual poderiam cultivar seus sítios e roçados ${ }^{17}$, criar tantos animais quanto desejassem e trabalhar para o patrão apenas quando necessitassem de dinheiro. Tudo isso pressupunha a presença do dono e não implicava a idéia da propriedade para o trabalhador. Explicar 0 ato de ocupar os engenhos como o produto de uma vontade prévia de possuir a terra não se sustenta, portanto, à luz dos conhecimentos disponíveis.

0 desemprego resultante da crise da agroindústria açucareira poderia ser uma explicação alternativa e atraente para dar conta das ocupações, eé dela que se valem os sindicalistas e os militantes para justificar 0 afluxo aos acampamentos: uma vez perdido o emprego, os trabal hadores teriam atendido aos convites e ido para os acampamentos. 0 problema é que sempre houve desemprego na entressafra da cana, no período entre março eagosto, quando ocorre o que se denomina tranca de inverno (cf. Sigaud, 1979, pp. 167-204). Ainda que com a crise essa situação tenha se agravado - e as ocupações tenderam a ocorrer exatamente ao término da moagem - , estar desempregado não parece ser condição suficiente para estar nos acampamentos. M ilhares de trabalhadores sem emprego preferiam continuar fazendo biscates a ir instalar-se sob a lona preta e recusavam os convites com 0 argumento de que não queriam a terra. Por outro lado, outros trabal hadores com um contrato de trabalho em vigor participavam das ocupações e montavam suas barracas, tratando de conciliar a presença no acampamento com o trabalho formal para o patrão, como aqueles de Pedra de Amolar, engenho da U sina C ucaú, queformaram o núcleo da ocupação do engenho M ato Grosso em Rio Formoso, em 1999.

O s trabal hadores que entre 1997 e 2000 se encontravam nos acampamentos afirmavam que lá estavam para pegar terra. Tinham origens sociais e trajetórias distintas, como já foi assinalado. A análise de suas histórias revela uma diversidade de situações precedentes à sua entrada no acampamento: alguns haviam perdido o emprego; outros ficaram sem casa após uma grande enchente ocorrida em Rio Formoso, em 1997; outros ainda queriam recomeçar a vida após uma crise familiar (separação, doença ou morte); ou sentiram-se atraídos pela presença de conhecidos e parentes no acampamento e pela proximidade deste com o local de moradia; e alguns aceitaram o convite porque tinham relações estreitas com militantes e sindicalistas e neles confiavam.

Amaro Santino encontrava-se no Brejo em setembro de 1997. H avia entrado no acampamento no dia 27 de maio, um mês e meio depois da 
ocupação. Tinha 48 anos e dezoito filhos, dos quais quinze viviam com ele. $\mathrm{N}$ ascido em Sirinhaém, havia morado 29 anos em um engenho da U sina Trapiche, mas se desentendera com o cabo do engenho e preferiu ir embora: entregou a ficha (demitiu-se) e foi para Tamandaré, onde residia um irmão. O uviu falar do Brejo pelo rádio: "Eu digo: o engenho Brejo está com problema com o Incra. Chamando bastante gente [a referência é a um programa de rádio mantido pelo M ST ]. Aí também houve este problema comigo lá [em Trapiche]. Aí eu digo: vou-me embora lá para o Incra [Brejo]".

Edmilson foi um dos primeiros a entrar no Brejo. No dia da ocupação, estava indo para a feira quando cruzou com D edé, militante do M ST, que conhecia de vista e que o chamou para 0 acampamento, dizendo que era um movimento certo, e pediu-Ihe que arranjasse mais gente. Embora nunca tivesse participado de uma ocupação, a idéia não Ihe era estranha. Ele trabalhava em Ilhetas, engenho da Central Barreiros que, como os demais, estava sem pagar salário. Assíduo às reuniões sindicais, já ouvira falar de várias ocupações.

N azareno, acampado no Brejo, morava em Tamandaré e vivia de vender frutas, peixe e caranguejo preparados por sua mulher.

18. O sdepoimentosrelativos ao engenho Brejo foram coletados em setembro de 1997 pela autora.
Aí fiquei aí, andando, aí sempre passando aqui [Brejo]. Aí vi esse negócio desse movimento. Aí quem me falou foi Zezinho. Zezinho é um militante, não é? E um coordenador. Aí eu fui gravando, gravando [o que ele dizia]. Aí um dia eu vim aqui. Aí falei, os meninos disseram [para ficar]... Aí eu fiz esse barraquinho aqui ${ }^{18}$.

Palhaço morava em Rio Formoso e foi acampar em M amucaba em 1999:

Aí, meu pirral hinho adoeceu, sabe? A catinga da maré, a catinga dalama podre- é, da maresia - , aí deixei, eu disse: eu vou vender esse barraco aqui, aí eu vendi, dei em mercadoria pra mulher, e a mulher foi para a casa da mãe dela, passar quinze dias na casa da mãe dela, e eu vim aqui pr'os sem-terra.

Dalvino, originário do Agreste, também acampou em M amucaba, em 1999:

Foi quando vim pr'aqui, atrás de serviço, novamente. Fiquei aqui, bati, bati, bati, não arranjei serviço nas empresas, nas usinas, aí vinha embora de novo pro sertão. 
M as foi tempo que um cara, um colega meu aí disse: "vai pr'os sem-terra!". Aí eu vim pr'aqui [acampamento de M amucaba] ${ }^{19}$.

19. O sdepoimentosre lativos ao engenho $\mathrm{M}$ a-

Em meio à tamanha diversi dade compartilhavam, no entanto, uma crença: a de que uma vez debaixo da lona preta poderiam, no curto prazo, melhorar suas condições de vida: ter terra para plantar e criar animais, e mucabaforam coletados por David Fajolles em setembro de 1999. crédito do governo para construir uma casa e produzir e, sobretudo, poder estabelecer-se por conta própria sem depender de um patrão.

Assim Amaro Santino (Brejo) contava que "quis pegar um terreno [pedaço de terra] para trabalhar mais meus filhos para deixar de ser obrigado a estes patrões". D aniel Pedro, acampado no Brejo, dizia:

Porque eu estou com 44 anos. É, 44 anos de sofrimento na empresa, entendeu? E não adquiri nada. Q ue eu trabal hei este tempo todinho para os outros e não adquiri nada. E eu trabal hando. Agora vou tentar. Porque eu trabalhando para mim não adquiri. Também não tenho nada contra a sorte. Porque perdido por perdido eu já estou, certo? [...] Acho que o melhor futuro meu é isso aí [o acampamento]. Também, que se eu perder, não estou perdendo nada [...]. Vou jogar na vida, na sorte [...].

E também Edmilson (Brejo):

Q ue eu queria... eu tenho vontade de trabal har para eu... [trabalhar] para os outros, o movimento caiu. Eu trabal hando para eu não cai. Eu estou andando para frente. Porque tenho filha, mais a mulher; [trabalhando] para os outros eu vou para baixo. $\mathrm{N}$ ão vai dar certo mais.

A crença de que um futuro melhor passava pela lona preta constitui-se assim em um elemento decisivo para explicar e compreender a disposição dos trabalhadores de se instalarem nas terras dos patrões. Como essa crença teria surgido é difícil, senão impossível, reconstituir. Pode-se apenas indicar a sua existência e formular a hipótese de que se teria constituído progressivamente, a partir de Camaçari. Alguns participantes daquela ocupação contam que no início poucos iam às reuniões preparatórias, pois desconfiavam do que Ihes era dito e temiam o que lhes pudesse vir a acontecer. Progressivamente o grupo foi aumentando. A presença dos sindicalistas de Rio Formoso naquelas reuniões certamente revestiu-as de credibilidade e contribuiu para que as resistências fossem sendo desmontadas. Q uando, a 
20. Para uma análisedo significado da ida para - Sul no mundo dosengenhos, ver Garcia Jr. (1990).

21. Estudos feitos em acampamentos no estado do Rio de Janeiro por Ernandez (2003) e em São Paulo por Loera (2004) indicam estar em jogo uma lógica nas saídas semelhanteà que identificamos na mata pernambucana. partir de 1993, o Incra começou a desapropriar as terras ocupadas, a crença ganhou força e solidez - as pessoas passaram a ter menos medo e menos dúvidas a respeito da pertinência de entrar nas terras.

0 fato novo nesse momento é a crença de que debaixo da lona preta poderiam almejar um futuro melhor. $\mathrm{N}$ a década de 1990, junto com a ida para o Sul do país ${ }^{20}$ ou para o Recife (a capital de Pernambuco), a mudança de emprego e de patrão, a assinatura da carteira de trabalho, a lona preta passa a fazer parte do repertório das possibilidades de "melhorar de vida". Tratava-se de uma alternativa nova, mas ainda assim uma alternativa, como qualquer outra. Interpretando-a dessa forma, pode-se melhor explicar fatos que permaneceriam obscuros se encarássemos a ida para os acampamentos como produto de uma conversão à "luta pela terra", como análises encantadas sobre movimentos sociais sugerem. Um desses fatos é a saí da dos acampamentos. Q uando um indivíduo passa a fazer parte de uma ocupação, crê e aposta nas possi bilidades da lona preta. O s despejos, os ataques das milícias privadas, a morosidade do processo de desapropriação do engenho ("essa terra não vai sair", costumam dizer) contribuem para produzir o desânimo, abalam a crença e a convicção de estarem fazendo uma boa aposta. Se, nessas circunstâncias, surgir outra possibilidade que para o trabalhador pareça mais atraente, ele não hesitará em ir embora. A partida não si gnifica a perda da crença. M uitos dos trabal hadores depois de al gum tempo regressavam ao mesmo acampamento ou entravam em outro21.

A crença nas possi bilidades abertas pela lona preta não é generalizada na mata pernambucana. $M$ as o fato de não crer nelas hoje não implica não crer amanhã. D esde 1997 mantive contato com muitos trabalhadores que a princípio não queriam nem ouvir falar em pegar terra e que posteriormente encontrei em um acampamento. Por outro lado, a crença não produz efeitos automáticos. M uitas vezes aqueles que acreditam nessa possibilidade preferem aguardar uma oportunidade melhor. De um ponto de vista sociológico, o que importa é que essa crença passou a figurar no horizonte de possibilidades.

A implantação da forma acampamento na mata pernambucana foi produto de uma mudança na figuração social (cf. Elias, 1986, pp. 154-161), favorecida por uma conjugação de condições sociais: a crise entre os patrões, a atuação do M ST, a inflexão dos sindicalistas e a gênese de uma nova crença. Para identificá-las foi necessário estranhar a existência dos acampamentos e perguntar: como eles se tornaram possíveis? Chegar a esta conclusão não teria sido possível se eu ignorasse a história das relações 
sociais e escolhesse buscar uma causa que determinasse um resultado, fosse ela "econômica", "política" ou "cultural", quaisquer que sejam os sentidos que se atribuam a esses termos.

Um ato fundador e legitimador

A entrada nos engenhos e a instalação dos acampamentos não ocorre ram num quadro preexistente de conflitos por terra. 0 exame da conjuntura no período que antecedeu as ocupações revela a inexistência de sinais de descontinuidade marcantes nas relações sociais. $\mathrm{H}$ avia interrupção de pagamento, como em Amaragi, Sauezinho, Saué Grande e Coqueiro; morte do dono, como em Cipó; entrega dos engenhos ao Banco do Brasil para o pagamento de dívidas pela $U$ sina $C$ entral Barreiros, como nos casos de Bre jo, Serra d'Água, M inguito, M ascatinho e Jundiá de Cima. Todas essas situações poderiam ter sido enfrentadas de forma costumeira, por meio de processos na Justiça do Trabal ho ou pela espera da chegada de novos donos ${ }^{22}$, e não necessariamente evoluiriam para a desapropriação das terras.

Foram os movimentos que, ao promoveram a entrada nos engenhos eos acampamentos, produziram uma inflexão no rumo dos acontecimentos: criaram um conflito de terra ali onde el e não existia e solicitaram ao Incra a desapropriação. N ão cabe aqui especular o porquêda ocupação daqueles engenhos, uma vez que se sabe que era esse o objetivo dos movimentos naquele momento e que aqueles engenhos, salvo Serra d'Água e M inguito ${ }^{23}$, pode riam se enquadrar nos novos critérios do Incra. Trata-se tão-somente de destacar que foi por meio da forma acampamento que problemas passíveis de uma solução costumeira foram transformados em um conflito por terra.

O Incra, por sua vez, aceitou a legitimidade dos procedimentos: reconhe ceu os movimentos como representantes autorizados a solicitar desapropriações, acatando suas demandas, e os participantes das ocupações como pretendentes legítimos à terra, dando-Ihes uma parcela. Conferiu também tanto aos movimentos como aos partici pantes dos acampamentos uma existência oficial em seus registros. Assim, nas tabelas referentes às ocupações, nomeadas como "áreas de conflitos" (conflitos que, como se viu, foram criados pelos movimentos), figuram, ao lado das colunas com informações relativas à localização do conflito, ao tamanho da propriedade, ao número de famílias residentes, uma coluna com o número de famílias acampadas e outra com o nome do movimento que esteve na origem da ocupação. N os formulários destinados a cadastrar os futuros parceleiros, figura o "acampa-
22. D esde que os dirétostrabalhistasforam estendidos ao campo, em 1963, os trabalhadores dosengenhospassaram a ajuizar ações na Justiça contra os patrões. Após o golpe militar, a prática foi privilegiada pelossindicalistasesetornou aformapor excelênciadeenfrentamento com os patrões (cf. Sigaud, 1999). A mudançadedono, por outro lado, era um fato corriqueiro. Ela se fazia com alguma tensão, mas passado o período de adaptação ao estilo do novo dono as relações se equilibravam.

\section{Essesengenhoseram} produtivos, segundo os critérios do Incra, e estavam arrendados. Foram desapropriadosporqueaU sinaC entral Barreiros, a proprietária, os havia entregado ao Banco do Brasil. 
24. Após o pedido de desapropriação, o Incra envia uma equipe detécnicosao engenho para proceder à vistoria. Se constatada a improdutividade, dará andamento ao processo. A documentação é enviada para Brasília, ao Incra nacional, que a submeteao presidente da República. C abe a ele assinar 0 decreto estabelecendo que a propriedade não cumpre sua função social. Seguese a desapropriação, na qual o proprietário recebe, pela terra, umaindenização em títulos da dívida agrária (TDA) com valor de mercado e, pelas benfeitorias, uma indenização em dinheiro.

25. A maioria dosacampamentos da mata pernambucanafoi constituída pelo grupo que ocupou 0 engenho. $\mathrm{H}$ á casos, no entanto, deacampamentosmontadospor moradoresparareivindicar a desapropriação. Foi o queocorreu em Amaragi, Sauezinho, Saué Grande e Coqueiro. do", categoria sem amparo legal, ao lado de outras reconhecidas pelo direito, como trabalhador rural, posseiro etc.

Como mais de $90 \%$ das desapropriações feitas pelo Incra contemplam as ditas áreas de conflito, ocupar engenhos e neles montar acampamentos, ou, dito de outra forma, valer-se da forma acampamento, tornou-se um recurso incontornável. Esse é o ato que cria o conflito por terra e desencadeia 0 processo que poderá desembocar na desapropriação ${ }^{24}$. 0 caso do engenho Tentúgal, de propriedade da U sina Central Barreiros, no município de São José da Coroa G rande (extremo sul do litoral), constitui nesse sentido um caso exemplar. Com a crise da usina, em situação de falência, os trabalhadores que residiam e trabalhavam no engenho viram na lona preta uma solução para seus problemas. Sabiam que sem um movimento à frente do processo não conseguiriam coisa alguma. Procuraram então os sindicalistas do município e pediram que organizassem um acampamento no engenho, que no entanto logo se desfez por falta de acompanhamento dos sindicalistas (conforme versão dostrabalhadores). Ao saberam quehavia militantes do M ST na área, apelaram a eles para que fizessem novo acampamento e solicitassem a desapropriação. Em 1999, o acampamento foi remontado, não com a entrada dos trabalhadores nas terras, uma vez que os acampados já residiam no engenho, mas com a montagem do acampamento com a bandeira do M ST e as lonas pretas, símbolos indicadores da questão de terra. 0 s donos pediram a reintegração de posse e o acampamento foi desmontado, deixando que os participantes continuassem residindo ali, mas com a destruição das barracas e o confisco da bandeira. N os anos seguintes, o acampamento foi remontado várias vezes e em 20020 Incra desapropriou Tentúgal. Este caso, que não se ajusta à norma seguida na maioria das ocupações ${ }^{25}$, tem a virtude de mostrar o quanto o recurso à forma acampamento já havia adquirido um caráter imperioso: não bastava encaminhar um pedido de desapropriação, era preciso fazêlo de modo adequado. A forma é o modo.

As ocupações de terras com montagem de acampamentos constituem uma linguagem simbólica, um modo de fazer afirmações por meio de atos, e um ato fundador de pretensões à legitimidade. Ao promover uma ocupação e um acampamento, o movimento diz ao Incra que deseja a desapropriação das terras, ao proprietário, que quer suas terras, e aos outros movimentos, que aquela ocupação tem um dono. Essa linguagem é bem compreendida por todos: o Incra entende que há um pedido de desapropriação e desencadeia o processo, o proprietário percebe a possibilidade de 
ficar sem suas terras e age na defesa de seus interesses, solicitando a reintegração de posse, e os outros movimentos respeitam a bandeira do concorrente e não ocupam aquela terra. Com o ato de ocupar, os movimentos legitimam suas pretensões à desapropriação e ao reconhecimento de que aquela ocupação é sua. Ao montar sua barraca, o trabalhador diz que quer a terra. Essa afirmação está dirigida ao I ncra, que no momento de selecionar os futuros parceleiros irá contabilizar os que se encontram debaixo da lona preta; ao movimento, queo incluirá em suas listas a serem apresentadas ao Incra; e aos demais que se encontram no acampamento, que irão reconhecê-lo como al guém que quer a terra. A barraca legitima a pretensão a pegar terra; éa prova material do interesse a ser contemplado no momento da redistribuição das terras. 0 estar debaixo da lona preta é representado como um sofrimento que torna aqueles que a isso se submetem merecedores da recompensa terra. Em alguns casos, quando a ocupação se prolongava por muito tempo, como em M amucaba, chegou-se a estruturar-se uma hierarquia de legitimidade, a partir de critérios como o tempo de permanência no acampamento, a participação nas atividades, a presença constante, a coragem demonstrada nos momentos de despejo ou de enfrentamento com as milícias privadas enviadas pelos proprietários para atacar os acampamentos ${ }^{26}$. Isso não produzia efeitos para as seleções do Incra; servia, no entanto, para classificar os indivíduos entre os mais e os menos merecedores.

As desapropriações ocorridas na mata pernambucana têm sido, portanto, o resultado de um processo desencadeado pelas ocupações e acampamentos, que caracterizaram uma situação de conflito por terra assim reconhecida pelo Incra. G raças à legitimidade conferida por esse organismo, a forma acampamento tornou-se a forma apropriada de fazer demandas. A sanção do Estado contribuiu assim para que ocupar terras e instalar-se em barracas viesse a se constituir em atos destinados a legitimar pretensões dos movimentos e dos indivíduos. Sobre aqueles que tinham interesse em fazer viver um movimento ou em pegar terra, abateu-se a coerção de passar pela forma.

\section{Dependência recíproca e relações de concorrência}

Em suas manifestações nos espaços públicos, as autoridades governamentais, sobretudo as do M inistério do D esenvolvimento Agrário e do Incra, e os representantes dos movimentos tendem a entreter uma retórica belicosa, como se suas relações fossem de enfrentamento permanente. As-
26. Essa hierarquia foi identificadapor Fajolles (2000) no acampamento de M amucaba (cf. Sigaud et alli, 2001, pp. 65-69). 
27. Um bom exemplo foi o episódio da M archa $\mathrm{N}$ acional dos Sem Terra. Ver a respeito os extratos dematériaspublicadas pela imprensa apresentadas por Chaves (2000, pp. 265341). sim, nosúltimos dez anos, a mídia vem divulgando, com bastante freqüência, declarações de autoridades nas quais se afirma que a reforma agrária será feita nos termos da lei e que não serão aceitas violações da ordem constitucional (invasões de propriedades privadas) ${ }^{27}$. D a parte dos movimentos, são habituais tanto as acusações de que o governo não realiza a reforma agrária, como as ameaças de novas ondas de ocupações de terra. 0 tom das hostilidades elevou-se durante os oito anos do governo Fernando $\mathrm{H}$ enrique encontra-se bastante amenizado desde o início do governo Lula. O ra, essa retórica, ainda que remeta a tensões entre as partes, oculta as relações de estreita cooperação e dependência entre Estado e movimentos.

Até o presente momento o Estado brasileiro não pôs em marcha uma política, nem tópica, nem em larga escala, de desapropriação de terras improdutivas, que a C onstituição e a regulamentação de 1993 autorizariam implementar. $\mathrm{N}$ a ausência de uma política própria para proceder às desapropriações, o governo tem dependido dos movimentos, que lhe indicam, por meio das ocupações e dos acampamentos, as fazendas a serem objeto de sua intervenção. N esse sentido, pode-se afirmar que os movimentos têm fornecido as diretrizes para a política do Estado brasileiro em relação à questão fundiária: as fazendas desapropriadas são aquelas que foram ocupadas. Basta cotejar as listas de desapropriações feitas nos últimos três governos (Itamar Franco, Fernando H enrique Cardoso e Lula), e fornecidas pelo I ncra, com as das ocupações e dos acampamentos fornecidas pelos movimentos para constatar a relação estreita entre desapropriações e ocupações. O s funcionários do Estado justificam as desapropriações al egando tratar-se de áreas de conflito. Esta é seguramente uma linguagem que sobreviveu de um tempo no qual eram efetivamente desapropriadas áreas onde havia um conflito preexistente, como tendeu a ocorrer na Amazônia, onde foram registrados nos anos de 1970 e 1980 enfrentamentos sangrentos entre posseiros e grileiros. O ra, como já foi visto aqui, quem cria o conflito são os movimentos. A ocupação e o acampamento caracterizam uma situação de conflito elhe dão visibilidade. A linguagem dasáreas de conflito tem efeitos eufemizadores que ocultam o caráter arbitrário do conflito.

O Estado depende ainda dos movimentos para selecionar os destinatários da redistribuição das terras desapropriadas, escolhidos entre os que participam das ocupações e que foram reunidos pelos movimentos. C ontrariamente ao senso comum, não existe uma massa de sem-terra ansiando pelo acesso à terra; os movimentos criam a demanda por terra ao convidar trabalhadores para ocupar as fazendas. São eles que Ihes abrem a possibili- 
dade de ter acesso a uma terra com a qual nunca haviam sonhado, como foi possível constatar em larga escala na pesquisa feita entre os assentados após a desapropriação nos engenhos da mata pernambucana ${ }^{28}$. Ao aceitarem 0 convite e se instalarem nos acampamentos, os indivíduos tornam-se semterra, porque passam a reivindicar a terra para si. Começam então a se identificar dessa forma, que é a modalidade apropriada de se representar no espaço dos acampamentos, e passam também a ser visto pelos demais, do campo e da cidade, como sem-terra. $\mathrm{N}$ ão se costuma considerar sem-terra o trabalhador que vive nas pontas de rua, sobrevivendo de trabal hos eventuais e de biscates, ou os trabal hadores contratados nos engenhos: eles não estão envolvidos em ocupações e acampamentos, condição indispensável para serem dessa forma identificados. O s movimentos criam, portanto, não apenas a demanda como também as condições de possibilidade de se tornar um sem-terra e vir a ser contemplado pela reforma agrária.

D e sua parte, os movimentos dependem fortemente do Estado para levar adiante seu programa de ocupações de terras, pois os benefícios a serem obtidos constituem um poderoso argumento para chamar as pessoas para as ocupações. Em seus relatos a respeito do convite de que foram alvos, os trabalhadores referiam-se com freqüência ao fato de Ihes haver sido dito que o Incra estava dando terras; que as terras para onde iriam eram improdutivas e, portanto, seriam desapropriadas; que se fossem para o acampamento receberiam cestas básicas dadas pelo mesmo Incra ${ }^{29}$; que quando houvesse a desapropriação teriam acesso a créditos para fazer uma casa, se sustentarem por algum tempo até poderem começar a produzir e ainda teriam recursos para tocar a produção. C ada desapropriação de um engenho ocupado e cada liberação de créditos para áreas de assentamentos confirmam a justeza do que é anunciado e favorecem a aceitação de novos convites para futuras ocupações. Assim, a dinâmica das ocupações é tributária da política de Estado. Sem ela os movimentos não teriam esperanças fundadas a oferecer a seu público alvo e encontrariam dificuldades para reunir pessoas para as ocupações. $N$ ão teriam também se fortalecido, nem se multiplicado, como ocorreu na mata pernambucana, onde são contabilizados nove movimentos (cf. Rosa, 2004, pp. 172-173).

Incra e movimentos estão assim vinculados por laços de dependência recíproca e de cooperação tácita. Como essas relações se inscrevem numa figuração, nos termos de N orbert Elias, na qual há indivíduos vinculados a outros poderes da República, como o Judiciário, a outros movimentos e também a outros atores, como os proprietários, elas tendem a ser comple-
28. Foi no âmbito de uma pesquisa em curso sobre os assentamentos de Rio Formoso e Ta mandaréquepudecons tatar que ostrabalhadores que haviam participado dos acampamentos nunca haviam pensado na possibilidadede vir ater sua própriacasa e um pedaço de terra dentro dosengenhosdos patrões.

29. N os acampamentos pesquisados houve, em al gum momento, distribuição decestas básicas. Embora a distribuição fosse intermitente, a possibilidademesmade ter acesso a ela constituía um atrativo importante para os trabaIhadores que, fora dos acampamentos, não seriam contemplados. 
xas e tensas. Assim, a maioria das desapropriações na mata pernambucana foi feita após uma intensificação da pressão dos movimentos sobre o Incra, como por exemplo as de Sauezinho, Saué G rande, Coqueiro, Cocal e C ocalzinho (engenhos da U sina Santo André localizados em Tamandaré), que só se efetivaram, em fins de 1999, após um acampamento de mais de 45 dias de cerca de cem trabal hadores daqueles engenhos em frente à sede do Incra, no Recife. Contra essas desapropriações, interpunham-se os donos da U sina Santo André, com o apoio de políticos de peso no cenário nacional. Via de regra o que aparece, porque objeto de atenção da mídia, é a tensão. Procurou-se aqui enfatizar a dimensão oculta da dependência e da cooperação que tem contribuído fortemente para entreter a engrenagem da forma acampamento.

Finalmente, caberia destacar que a generalização da forma acampamento tem sido tributária também das relações de dependência que vinculam cada movimento com as pessoas que mobilizou e conduziu com sucesso à obtenção da terra, bem como das relações de concorrência entre os movimentos. 0 s indivíduos que obtiveram a terra e acesso aos créditos, por intermédio de ocupações, se sentem devedores ao movimento que tornou isso possível. A dívida implica obrigações, como leal dade e cooperação, eé descrita como um compromisso. O s movimentos contam, portanto, com os antigos acampados, ehoje detentores deuma parcela, quando há marchas e manifestações a promover e, sobretudo, quando setrata de fazer novas ocupações. Eles vão para fazer número, ensinar a técnica de ocupar, animar os neófitos e, com o seu exemplo, mostrar que a esperança na lona preta tem fundamento. Em todas as ocupações havia um núcleo constituído por as-

30. Esse tipo de leal dadefoi encontrado também nos acampamentos estudados por Ernandez (2003) no estado do Rio de Janeiro, por Loera (2004) em São Paulo e por Brenneisen (2003) no Paraná. sentados ${ }^{30}$. 0 capital simbólico (prestígio) e o poder relativo (posição na correlação de forças) dos movimentos são constituídos por aquilo que é reconhecido como seus feitos e suas vitórias: as ocupações e as desapropriações. O s movimentos competem para acumular cada vez mais capitais, o que se constitui em elemento decisivo para entender a espiral de ocupações (cf. Smircic, 2000; Sigaud, 2000; Sigaud et alii, 2001; Rosa, 2004).

\section{Digressão sul-africana}

Em virtude da legislação instituída pela administração colonial britânica e pelos governos que implantaram o apartheid, a maior parte das terras da África do Sul encontra-se nas mãos dos brancos, ou seja, 11\% da população controla $69 \%$ das terras. 0 governo que se estabeleceu com o fim do 
apartheid, em 1994, instituiu como uma de suas prioridades a realização da reforma agrária, para democratizar o acesso à terra, reparar "injustiças" cometidas em relação à população negra e assegurar um desenvolvimento rural "sustentável". Três programas foram então criados a partir de leis votadas pelo Congresso: a restituição das terras confiscadas aos negros em 1913, a ser feita mediante solicitação ao Land Claims Commission; a redistribuição de terras mediante a transação entre compradores e vendedores, com recursos garantidos pelo governo (algo semelhante ao que Fernando H enrique Cardoso tentou implementar no Brasil com o Banco da Terra, uma criação do Banco $M$ undial); ea regularização da posse da terra para os que vivem em terras comunais (nas chamadas homelands, as terras ocupadas pelas tribose controladas por chefes tribais) ou em terras de fazendeiros brancos (calcula-se que exista 1 milhão de tenants ${ }^{31} \mathrm{em}$ terras de brancos).

O s estudiosos da questão fundiária convergem no sentido de indicar quea reforma agrária não se constituiu em prioridade para os governos pósapartheid, que a ela destinaram parcos recursos e não criaram estruturas institucionais para implementá-la de forma eficaz. N esse sentido, não haveria grande diferença entre Brasil e África do Sul. Também aqui, desde o governo $\mathrm{FH} \mathrm{C}$, persistem as críticas de que os recursos para a reforma agrária têm sido insuficientes, o que não surpreende, pois as economias dos dois países têm estado submetidas às diretrizes do Fundo M onetário Internacional (FMI) e, portanto, ao controle estrito dos gastos públicos. U ma diferença importante, no entanto, diz respeito ao fato de que os movimentos têm desempenhado um papel decisivo no Brasil para a ampliação de recursos e sua liberação, o que não é registrado na África do Sul. As ocupações de prédios públicos, sobretudo de bancos oficiais, promovidas pelo M ST e pelo movimento sindical se inscrevem nessa estratégia.

O rganizações não-governamentais nucleadas na $\mathrm{N}$ ational Land Committee (N LC) têm estado à frente das reivindicações relativas à questão de terras. C ontroladas por ativistas de direitos humanos e advogados, focalizaram sua ação na defesa de direitos (cf. James, 2002). Com o apoio da N LC, o Landless People's M ovement foi criado em 2001, passando a ser a primeira organização constituída a partir de indivíduos de origem rural e que reivindica o estatuto de um movimento social. $H$ á indicações de que depende do apoio financeiro das $0 \mathrm{~N} \mathrm{Gs}$, o que limita sua margem de ação, sobretudo no que diz respeito aos enfrentamentos com o governo, com o qual muitas das $\mathrm{O} N \mathrm{G}$ s estão alinhadas e pouco dispostas a romper. Essas características da organização no campo sul-africano contrastam fortemen-
31. Tenants são aqueles que vivem no interior das propriedades. Poderiam ser aproximados aosmoradoresdasgrandes plantações do N ordeste e aos colonos das fazendas de café. Eles trabalham na propriedade, têm o direito de cultivar suas próprias lavouras e criar seus animais. 
te com aquelas no campo brasileiro. Entre nós, a organização dos trabal hadores rurais data dos anos de 1950, quando sequer existiam O NGs. As organizações que se sucederam, como as Associações de Lavradores, as Ligas Camponesas, o M ovimento dos Agricultores Sem-Terra (M aster), a União dos Lavradores eTrabalhadores na Agricultura do Brasil (UItab), os sindicatos de trabalhadores rurais, O M ST, foram apoiadas por partidos políticos, como o PCB, o PT B do Rio Grande do Sul, por militantes de esquerda (como os trotskistas e a esquerda católica), pelo governo federal (no curto período de João Goulart), pela I greja C atólica e, mais recentemente, pelo seu braço rural, a C omissão Pastoral daTerra. $N$ ão seria exagerado dizer que todas lograram obter sua autonomia em relação àqueles que as patrocinaram. 0 movimento sindical na mata pernambucana constitui um exemplo eloqüente disso, em relação à I greja C atólica e ao terceiro governo de M iguel Arraes. Por outro lado, a existência das organizações de trabalhadores em momentos cruciais da história das relações sociais no campo contribuiu para imprimir um outro rumo ao processo de transformação em curso, e também aqui o exemplo é a mata pernambucana. G raças à sua forte implantação, os sindicatos conseguiram obstaculizar, por meio de processos judiciais, a expulsão em massa dos trabalhadores das grandes plantações canavieiras que se desencadeou após a aprovação do Estatuto do Trabalhador Rural (ETR), em 1963 (cf. Sigaud, 1994). Já no caso sul-africano, a ausência de uma organização de trabalhadores rurais parece estar facilitando sobremanei ra as expul sões dos tenants das fazendas, desencadeadas também com uma mudança no ordenamento jurídico: os Tenants Acts (legislação referente aos tenants) de 1996 e 1997. Lá e cá, parece ser idêntica a intenção dos fazendeiros: esvaziar suas terras de possíveis candidatos a direitos sobre elas. Nos dois casos, os governos pouco fizeram para garantir os direitos que inventaram. 0 elemento distintivo éa existência de uma organização de trabalhadores em condições de se contrapor à força dos fazendeiros no caso brasileiro. Seria possível formular a hipótese de que, naÁfrica do Sul, os ataques às fazendas, os crimes de brancos contra negros e negros contra brancos, ou seja, essa forma não civilizada, para os padrões ocidentais, de regulação de conflitos, estejam relacionados à ausência de uma estrutura de representação de interesses e de organização e encaminhamento de demandas, aliada a uma história de ódio racial. É claro que outras condições sociais contribuem para que a regulação passe pelo recurso à força, como o controle exercido pelos fazendeiros brancos sobre a polícia e a justiça, que garante a eles a impunidade. 
Com os acontecimentos recentes no Zimbábue, como a tomada das terras dos fazendeiros brancos patrocinada pelo governo M ugabe, um grande medo parece ter tomado conta da elite branca sul-africana, dos investidores internacionais e o do próprio governo, não apenas pela proximidade geográfica e histórica dos dois países, mas pela acolhida favorável das tomadas de terra entre os pobres sul-africanos. Para tranqüilizar as elites eo mercado, o governo tem reiterado que não tolerará as ocupações de terra e que a reforma agrária se fará estritamente nos termos da lei. A forte repressão à ocupação de Bredell se inscreve nessa lógica. Para o Brasil, o papel exercido pelo Zimbábue pertenceu a Cuba, no final dos anos de 1950 e início dos anos de 1960. 0 gol pemilitar de 1964 visou, entre outras coisas, a impedir uma "cubanização" do campo brasileiro. Como o golpe foi dado em nome da democracia, os militares tiveram que manter em funcionamento os tribunais e preservar as leis, dentre elas o ETR. As ocupações de terra pré-1964, as greves e as manifestações foram reprimidas, mas os sindicatos permaneceram abertos e puderam canal izar as demandas para as instituições jurídicas. As ocupações de terra do final da década de 1970, as que proliferaram nos anos de 1980 e se generalizaram na década seguinte, se inscrevem na longa história de enfrentamentos entre trabalhadores e suas organizações e os grandes proprietários ${ }^{32}$. Feitas fora dos marcos da legalidade, foram no entanto acolhidas como legítimas pelo Estado brasileiro, que desde o início respondeu desapropriando e redistribuindo as terras. É mais fácil compreender a repressão do governo sul-africano do que o acolhimento do governo brasileiro, mas essa é uma questão que escapa às ambições deste trabal ho. 0 que importa destacar aqui é que a dureza da repressão sulafricana tem inibido fortemente as ocupações. $\mathrm{N}$ a área de Pietermoritzburg (província de KwaZulu-N atal), entrevistei tenants em conflito com os fazendeiros, que os impediam de cultivar a terra e utilizar os pastos como tradicionalmente o faziam, eainda os ameaçavam de expulsão. Estavam familiarizados com as ocupações no Brasil e admiravam o M ST. Reagir aos fazendeiros por meio de ocupações era um projeto quenutriam, mas temiam levá-lo a cabo exatamente por causa da repressão que sabiam vi ria do governo e dos seguranças privados dos fazendeiros.

G raças a estudos etnográficos (cf. James, 2004), pude compreender que quando os tenants afirmam querer permanecer nas fazendas onde trabaIham, o que ambicionam é tão-somente segurança para continuar a ter acesso à terra para cultivo e pasto. $N$ ão querem se tornar proprietários, nem pequenos empreendedores rurais, idéia que prevalece nos projetos do go-
32. Pesquisaa respeito da sociogênese das ocupa ções de terra em andamento no M useu N acional, e por mim coordenada, mostra queasprimeiras ocupações do final dosanosde1970 estiveram relacionadas às ocupações do pré-1964, tanto as do Rio Grande do Sul, queiriam desembocar na criação do M ST, quanto no estado do Rio de Janeiro (cf. Rosa e Palmeira, 2004; Ernandez et alii, 2004). 
verno. N um país com alto índice de desemprego e grave problema de moradia, ter um lugar para "deitar a cabeça" (como dizia um interlocutor de James) já é um privilégio. No Brasil, prevalece também a retórica de usar a reforma agrária para o desenvolvimento da economia rural, o que pode até acontecer, mas não é com o objetivo de se tornar pequenos empreendedores que os indivíduos foram para debaixo da lona preta na mata pernambucana. 0 que os animava era a idéia de poder ter algo para si, livrar-se da dominação do patrão e poder se beneficiar das políticas de Estado.

\section{Conclusão}

As ocupações de terra no Brasil são reconhecidas como um fato notável dentro e fora das fronteiras nacionais. São freqüentemente vistas, em um registro positivo, como uma nova manifestação da "luta por terra", ou, em registro negativo, como o produto demoníaco da manipulação das massas por agitadores. Busquei explicar e compreender como elas se tornaram possíveis, sem cair nas armadilhas do despertar da consciência da massa dos sem-terra. Isso só foi exeqüível graças a determinadas opções metodológicas. Partiu-se da etnografia dos acampamentos e da comparação entre eles, o que permitiu identificar a existência de uma forma. Em seguida, problematizaram-se as condições de possibilidade de implantação de tal forma. Para tanto tratou-se de inscrever os acampamentos na história das relações sociais em que ocorriam e, sobretudo, procurou-se compreender a motivação dos que lá se encontravam. Como chamou a atenção quea reivindicação pela terra tivesse que passar por toda uma performance de barracas de lona preta e bandeiras hasteadas em mastros, perguntou-se sobre o que estava em jogo na montagem do acampamento para os movimentos e para os indivíduos: tratava-se de atos que tornavam legítimas as pretensões. Em seguida, procurei explicar a dinâmica e a institucionalização da forma por meio das relações de dependência recíproca e da concorrência que vinculam o Estado, os movimentos e os indivíduos. A comparação com o caso sul-africano permitiu evidenciar o quanto no Brasil as ações dos movimentos, suas relações com o Estado e as próprias políticas do Estado têm contribuído de forma decisiva para a institucionalização entre nós das ocupações de terra.

As ocupações não são um efeito da "luta por terra". N ão quero com isso dizer que ela não exista, mas evitar um olhar idealizador que tende a obscurecer as causas. A demanda por terra não é preexistente: é produzida 
pelos movimentos e alimentada pelas práticas do Estado. M as desde que haja indivíduos dispostos a atender aos convites dos movimentos e a crer na possi bilidade do acesso à terra, eles participam de ações que produzem o efeito de fazer existir uma "luta pela terra". Vários são os efeitos dessa "Iuta" - destacam-se, dentre eles, a condição de possibilidade da política de desapropriação do Estado brasileiro nos últimos vinte anos, a criação e o fortalecimento de movimentos e, sobretudo, o fato de que, graças a ela, centenas de milhares de indivíduos lograram obter a atenção do Estado brasileiro, beneficiando-se do acesso à terra e de políticas de crédito. N ão fosse essa "luta", muitos permaneceriam ignorados, como boa parte da população, ou apenas seriam alvo de programas pontuais e emergenciais. É certo que a base da análise é o caso de Pernambuco, mas um caso bem estudado ilumina o estudo de outros, fornece pistas para novas pesquisas e um modelo de análise.

Referências Bibliográficas

Asso ciation for Rural Advancem ent (AfRA). (2002), Theemergence of the Landless Peoplés M ovement in SA. Pietermoritzburg, ZA, AFRA.

BezerRa, Gregório. (1979), M emórias. Segunda parte: 1946-1964. Rio de Janeiro, Civilização Brasileira.

Brennelsen, Eliane. (2003), "Assentamento Sepé Tiaraju: persistências do passado, fragmentos do presente". In: M ARTINs, José de Sousa (org.). Travessias a vivência da reforma agrária nos assentamentos. Porto Alegre, Editora da U FRGS.

Cam Argo, Aspásia. (1973), Brésil N ord'Est: mouvements paysans et crise populiste. Paris. Tese de D outorado. Universidade de Paris, Terceiro Ciclo (mimeo.). . (1981), "A questão agrária: crise de poder e reformas de base (1930-1964). In: FAusto, Boris (org.). H istória geral da civilização brasileira. 0 Brasil Republicano. São Paulo, Difel, tomo III.

Chaves, Christine de Alencar. (2000), A marcha nacional dos sem-terra: um etudo sobre a fabricação do social. Rio de Janeiro, Relume Dumará.

Correa de Andrade, Manuel. (1964), A terra e o homem no Nordeste. São Paulo, Brasiliense.

- (1989), H istória das usinas de açúcar de Pernambuco. Recife, M assangana. \& AndRADE, Sonia Correia de. (2001), A cana-deaçúcar na região da mata pernambucana. Recife, CN Pq/FJN/UFPE.

ECKERT, Córdula. (1984), M ovimentos dos agricultores sem terra no Rio Grande do Sul: 1960-1964. Rio de Janeiro. Dissertação de M estrado. CPD A/U FRRJ. 
EIsen berg, Peter L. (1977), M odernização sem mudança: a indústria açucareira em

Pernambuco, 1840/1910. Rio de Janeiro/C ampinas, Paz e Terra/U nicamp.

ELIAS, N orbert. (1991), Q u'est-ce que la sociologie? M arselha, Editions de l'Aube.

Ernandez, M arcelo. (2003), "Zé Pureza": etnografia de um acampamento no norte

fluminense. Rio de Janeiro. Tese de D outorado. Programa de Pós-graduação em

Ciências Sociais da U niversidade do Estado do Rio de Janeiro.

; Guedes, M auro \& Figueira, Renata. (2004), "Sementes em trincheiras: a

luta pela posse da terra no Rio de Janeiro do pré-64". Trabalho apresentado no

seminário "O ficina de Pesquisa sobre Transformações Sociais no M undo Rural".

Rio de Janeiro, M useu Nacional, dez.

GarciA J R., Afrânio. (1983), Terra de trabalho. Rio de Janeiro, Paz e Terra.

- (1990), o Sul: caminho do roçado. São Paulo, M arco Zero.

G Ryn szPan, M ário. (1987), M obilização camponesa e competição política no estado do

Rio de Janeiro (1950-1964). Rio de Janeiro. Dissertação de M estrado. PPGAS/ Museu $\mathrm{N}$ acional/UFRJ.

HerediA, Beatriz. (1979), A morada da vida. Rio de Janeiro, Paz eTerra.

International Crisis Group (ICG ). (2004), Blood and soil: land, politicsand conflict

prevention in Zimbabwe and South Africa. Bruxelas, International Crisis Group.

J AM ES, D eborah. (2002), "Tenure reformed: policyt and practices in the case of South

Africa's landless people". Trabalho apresentado no M ax Planck Institute.

Jornal do Commércio. (1992), Caderno Cidades, Recife, 29 de abril, p. 2.

Lo era, N ashieli Cecília. (2004), A busca do território: uma aproximação à diversidade

do seu significado entre os sem-terra. C ampinas. D issertação de M estrado. D eparta-

mento de Antropologia Social, Universidade Estadual de Campinas.

M An ÇAn o, Bernardo. (2000), A formação do M ST no Brasil. Rio de Janeiro, Vozes.

M ello, M ário Lacerda de. (1975), 0 açúcar e o homem. Recife, M EC/Instituto Joaquim $\mathrm{N}$ abuco.

Palmeira, M oacir. (1971), Feira e mudança econômica. Simpósio de Pesquisas, Museu $\mathrm{N}$ acional/C entro Latino-Americano de Pesquisas em Ciências Sociais (mimeo.). . (1976), "C asa e trabalho: notas sobre as relações sociais na plantation tradicional". In: Actes du XLII Congrès des Américanistes, Paris.

RosA, M arcelo Carvalho. (2004), 0 engenho dos movimentos: reforma agrária e significação social na zona canavieira de Pernambuco. Rio de Janeiro. Tese de D outorado. Iuperj.

\& Palmeira, Isabel. (2004), "Fazenda Sarandi: considerações preliminares sobre a construção da legitimidade das ocupações de terra no R io Grande do Sul". Trabalho apresentado no seminário "O ficina de Pesquisa sobre Transformações Sociais no M undo Rural". Rio de Janeiro, M useu N acional, dez. 
Sigaud, Lygia. (1979), O s clandestinos e os direitos. São Paulo, D uas Cidades. . (1994), "D es Plantations aux villes: les ambigüités d'un choix". Études Rurales, 131-132.

. (1999), "Les Paysans et le droit: le mode juridique de règlement de conflits". Informations sur les Sciences Sociales, 38 (1).

. (2000), "A forma acampamento: notas a partir da versão pernambucana". N ovos Estudos Cebrap, pp. 73-92.

. et alii. (2001), "H istoires de campements". Cahiers du Bréill Contemporain, 43/44: 31-70.

SMIRCIC, Sergio Chamorro. (2000), Com a cara e a coragem: uma etnografia de uma ocupação de terras. Rio de Janeiro. Dissertação de M estrado. M useu Nacional/ PPGAS/UFRJ.

Sted ILE, João Pedro \& M AnçAn o, Bernardo. (1999), Brava gente: a trajetória do M ST e a luta pela terra no Brasil. São Paulo, Editora Fundação Perseu Abramo.

Stein Berg, Johnny. (2002), M idlands. Johanesburg/C ape Town, Jonathan Ball Publishers.

WILKIE, M ary. (1964), "A report on rural syndicates in Pernambuco". Rio de Janeiro, Centro Latino-Americano de Pesquisas em Ciências Sociais (mimeo.).

\section{Resumo}

As condições de possibilidade das ocupações de terra

O cupar terras e nelas montar acampamentos é, em nossos dias, a forma apropriada para reivindicar a reforma agrária no Brasil e dela se valem as organizações do mundo rural, como o M ST e o movimento sindical. 0 Estado tem conferido legitimidade à pretensão dos movimentos ao desapropriar as terras ocupadas e redistribuí-las. Esse fato recente na história nacional é examinado a partir de pesquisa realizada em Pernambuco, estado com o maior número de ocupações. 0 foco éa zona das plantações canavieiras, onde há grande concentração de acampamentos. 0 artigo inscreve as ocupações na história recente da região, mostra o que contribuiu para que se multiplicassem e analisa suas implicações. Ao final é feita uma digressão sobre a África do Sul, onde as ocupações, tidas pelos movimentos sociais como o procedimento adequado para obter do governo a distribuição de terras, não possuem a mesma magnitude. A comparação permite identificar as condiç̧ões sociais que no caso brasileiro têm favore cido a institucional ização das ocupações e no caso sul-africano as têm obstaculizado. Palavras-chave: 0 cupações de terra; M ovimentos sociais; Q uestão agrária; N ordeste; África do Sul. 


\begin{abstract}
The conditions of possibility of land occupations

Invading private lands and setting up encampments has now become the favoured means of pushing for agrarian reform in Brazil, a strategy used by rural organizations such as M ST (the Landless M ovement) and workers unions. The State has also legitimized these movements' aims to take over occupied lands and re-distribute them. Research conducted in Pernambuco, the state with the highest number of occupations, provides the basis for examining this recent aspect of Brazilian history. The article focuses on the rural zone formed by large-scale sugarcane plantations where many encampments are concentrated and situates the occupations in the context of the region's recent history, revealing the causes behind their multiplication and analyzing their implications. It concludes by turning to South Africa whereland invasionsconceived by social movements as the best procedure for obtaining land distribution from the Government - have failed to attain the same magnitude. This comparison allows us to identify the social conditions that have favoured the institutionalization of land occupations in Brazil while hindering them in South Africa.
\end{abstract}

Keywords: Land occupations; Social movements; Agrarian reform; N ortheast Brazil; South Africa.

Texto recebido em 25/ $11 / 2004$ e aprovado em 20/12/2004.

LygiaSigaud éprofessora do D epartamento de Antropologia do M useu N acional/UFRJ, pesquisadora do C N Pq e bolsistada Faperj. Publicou livros e artigos sobre 0 mundo dasgrandesplantações canavieiras do N ordeste e editou com Benoît deL'EstoileeFe derico N eiburg Antropologia, impérios e Estados nacionais. E-mail: Isigaud @alternex.com.br 